\title{
Dietary education must fit into everyday life: a qualitative study of people with a Pakistani background and type 2 diabetes
}

This article was published in the following Dove Press journal:

Patient Preference and Adherence

26 February 2015

Number of times this article has been viewed

\section{Nana F Hempler' \\ Sara Nicic' \\ Bettina Ewers ${ }^{2}$ \\ Ingrid Willaing'}

'Health Promotion Research, Steno Diabetes Center, Gentofte, Denmark; ${ }^{2}$ Nutrition and Food Services Department, Steno Diabetes Center, Gentofte, Denmark
Correspondence: Nana F Hempler Health Promotion Research, Steno Diabetes Center, Niels Steensens Vej 8, 2820 Gentofte, Denmark

Tel +45 40732591

Fax +45 44438235

Email nfhr@steno.dk
Background: The high prevalence of diabetes among South Asian populations in European countries partially derives from unhealthy changes in dietary patterns. Limited studies address perspectives of South Asian populations with respect to utility of diabetes education in everyday life. This study explores perspectives on dietary diabetes education and healthy food choices of people living in Denmark who have a Pakistani background and type 2 diabetes.

Methods: In-depth interviews were conducted between October 2012 and December 2013 with 12 participants with type 2 diabetes who had received dietary diabetes education. Data analysis was systematic and was based on grounded theory principles.

Results: Participants described the process of integrating and utilizing dietary education in everyday life as challenging. Perceived barriers of the integration and utilization included a lack of a connection between the content of the education and life conditions, a lack of support from their social networks for dietary change, difficulty integrating the education into everyday life, and failure to include the participants' taste preferences in the educational setting.

Conclusion: Dietary education that is sensitive to the attitudes, wishes, and preferences of the participants and that aims at establishing a connection to the everyday life of the participants might facilitate successful changes in dietary practices among people with a Pakistani background and type 2 diabetes. The findings suggest that more focus should be placed on collaborative processes in the dietary educational setting in order to achieve appropriate education and to improve communication between this population and health care professionals.

Keywords: dietary diabetes education, healthy food choices, Pakistani background, type 2 diabetes, patient perspectives, preferences

\section{Introduction}

In European countries, members of South Asian populations who originate from India, Pakistan, Bangladesh, and Sri Lanka are at a higher risk of developing overweight, obesity, and type 2 diabetes than are members of the host population. ${ }^{1-7}$ In Denmark, the largest group of South Asians comprises immigrants from Pakistan. ${ }^{8}$ The ageadjusted prevalence of type 2 diabetes in immigrants from Pakistan is approximately 14\%, whereas prevalence rates are 7.9\% among Pakistanis residing in Pakistan and 2.0\% among Danish-born people residing in Denmark. ${ }^{7,9,10}$

It is suggested that the increased prevalence of type 2 diabetes in South Asian populations derives from an interplay between life style and genetic factors. ${ }^{5}$ The greater prevalence of diabetes among South Asians settled in Europe than that among South Asians of similar cultural and genetic background in their country of origin suggests that health behavior, which includes dietary habits, plays a significant role in the development of diabetes. ${ }^{11}$ Studies also show that rates of diabetes complications, such 
as cardiovascular disease and mortality, are higher among South Asians with type 2 diabetes than among other population groups with type 2 diabetes. ${ }^{12}$ A recent review supports the contribution of health behaviors as factors for increased prevalence; after immigrating to Europe, members of South Asian populations tend to substantially increase their intake of energy and fat and reduce their intake of carbohydrates from recommended sources. ${ }^{11}$ Lifestyle changes, such as eating a healthier diet and being more physically active, are key factors in the prevention and care of type 2 diabetes. ${ }^{13}$ Excessive food and energy intake results in overweight and obesity, increases metabolic disturbances, and may induce poor glycemic control. ${ }^{13}$

In light of the increased prevalence of type 2 diabetes, dietary changes after immigration to European countries, and the increased risk of diabetes complications, the provision of appropriate dietary education to South Asian immigrants with diabetes is of particular importance. However, appropriate access to diabetes care, including diabetes education, consists of more than simply providing the service. ${ }^{14}$ Responsiveness to the health beliefs, practices, and cultural needs of persons with type 2 diabetes is required to provide equitable access to health care for diverse populations. ${ }^{14}$ A review of ethnicity and health service access in the United Kingdom identified three dimensions of equitable access to health care for ethnic minorities: 1) having equal access via appropriate information; 2) having access to services that are relevant, timely, and sensitive to people's needs; and 3) being able to use health services with ease and having confidence that one will be treated with respect. ${ }^{15}$ Consequently, equitable access to dietary education includes delivery of education in a context of appropriate information and sensitivity to the needs and preferences of the target group.

Cultural sensitivity can be conceptualized as having two dimensions. Surface structure matches materials and messages to the target population, and deep structure incorporates cultural, social, historical, environmental, and psychological factors that influence health behaviors. ${ }^{16}$ Culturally sensitive diabetes education targeting South Asian populations with type 2 diabetes has shown short-term effects on glycemic control and knowledge of diabetes. ${ }^{17,18}$ However, studies have not been successful in identifying culturally sensitive methods that target South Asians populations and have long-term, successful effects. ${ }^{19}$ According to Fagerli et al the process of translating dietary advice to migrant persons with type 2 diabetes is of particular importance if the health system is dominated by the majority population and the multicultural knowledge of health care professionals is limited. ${ }^{20}$
Qualitative studies have addressed the views and attitudes of members of South Asian populations with respect to food and food practices, ${ }^{21-24}$ but few studies have explored perspectives of South Asian groups on healthy food choices in connection with dietary education as part of the treatment for type 2 diabetes. ${ }^{20}$ The aim of this study is to provide perspectives on dietary education and healthy food choices in people with a Pakistani background and type 2 diabetes.

\section{Methods}

\section{Participants and data collection}

All participants lived in Denmark, had a Pakistani background, were diagnosed with type 2 diabetes, and had received dietary education in Denmark. Eleven were immigrants to Denmark from Pakistan, and one was Danish born with Pakistani parents. Participants included six women and six men between the ages of 34 and 70 . We used purposeful sampling techniques to select participants on the basis of variations in sex, age, and education level. Participants were recruited in one of two ways: 1) from a specialist diabetes clinic in the Copenhagen area through a Pakistani doctor or 2) from the family and friends of other participants. All participants had received dietary education at the same diabetes specialist clinic, but the education that was provided differed in content and in intensity for each individual. In Denmark, approximately $10 \%$ of patients with type 2 diabetes are treated in outpatient clinics such as the Steno Diabetes Center, and $90 \%$ are treated by general practitioners. The patients being treated at outpatient clinics had longstanding diabetes and among these patients was a high prevalence of complications. Patients at Steno Diabetes Center are offered at least one consultation with a dietitian. Patients can subsequently be referred to group-based dietary education or individual dietary education. Patients who do not speak Danish are offered individual dietary education. Counseling is based on national and international guidelines from the Danish Diabetes Association, the Diabetes Nutrition Study Group under the European Association of Diabetes, and the American Diabetes Association.

Participants were contacted by telephone and were provided with a verbal explanation of the study with assistance as needed from an interpreter. We interviewed a total of 12 participants until we reached saturation, which was defined as the point at which no new data resulted from additional data collection. Participants varied in characteristics such as duration of disease, country of birth (immigrant or descendant), age at immigration, type of treatment (oral medication and/or insulin), education level, employment status, and age (Table 1). 
Table I Characteristics of participants

\begin{tabular}{|c|c|}
\hline Characteristic & Number \\
\hline Total participants & 12 \\
\hline \multicolumn{2}{|l|}{ Sex } \\
\hline Male & 6 \\
\hline Female & 6 \\
\hline Age range (years) & $34-70$ \\
\hline \multicolumn{2}{|l|}{ Marital status } \\
\hline Married & 12 \\
\hline Born and raised in Denmark & I \\
\hline \multicolumn{2}{|l|}{ Age at immigration* } \\
\hline $1-18$ & 2 \\
\hline $19-40$ & 9 \\
\hline$>40$ & 0 \\
\hline Range of length of time lived in Denmark (years) & $20-37$ \\
\hline \multicolumn{2}{|l|}{ Occupation } \\
\hline Work & 5 \\
\hline Stay at home & 2 \\
\hline Retired & 5 \\
\hline \multicolumn{2}{|l|}{ Education level } \\
\hline Higher education & 3 \\
\hline Unskilled worker & 4 \\
\hline No formal education & 3 \\
\hline Unknown & 2 \\
\hline Interpreter required for interview & 3 \\
\hline \multicolumn{2}{|l|}{ Religion } \\
\hline Muslim & 11 \\
\hline Nonreligious & 1 \\
\hline
\end{tabular}

Note: *One participant was born in Denmark.

Five participants preferred being interviewed with their partners present. In two of these interviews, the partner participated actively. The interviews, which occurred between October 2012 and December 2013, lasted approximately an hour. A researcher with a Danish background (Nana F Hempler) conducted all interviews. Participants chose the interview location. Seven interviews were conducted in the participants' homes, four at a specialist diabetes clinic, and one at the participant's workplace. An interpreter fluent in Urdu and Punjabi facilitated three interviews. After the interviews, Hempler wrote case-based memos that reflected what was learned from each interview, the interviewer's impressions about the participants' experiences, and the interviewer's reactions. Interviews were recorded and transcribed verbatim in digital form.

Our aim was to explore participants' perspectives, experiences, and preferences regarding dietary education. We also asked open research questions concerning food preferences, everyday life, and life with diabetes. Emerging patterns and themes in initial interviews were used to adapt questions for subsequent interviews. Similarly, topics and research questions were adapted over the course of the interviews according to what participants expressed as most important to them.
This allowed more in-depth exploration of their perspectives and is consistent with a grounded theory approach, in which themes are subject to change as the interview data are collected and categories emerge. ${ }^{25}$ Interviews were supported by cultural probes containing illustrations of food, beverages, and social practices to engage participants and elicit their perspectives and preferences. ${ }^{26}$ Illustrations were adapted to the emerging themes and topics.

\section{Data analysis}

Data were analyzed by using an inductive approach of Glaser in which data moved from empirical generalization and on to theory. ${ }^{27}$ The qualitative software program Nvivo8 was used to systematize the data. First, a substantive coding of the interviews was performed. As many categories as possible were coded to "run the data open". ${ }^{28} \mathrm{New}$ categories emerged, some of which were fit into existing categories. Tentative links between categories appeared in the process of data analysis. The written memos became part of the comparison work. ${ }^{27}$ When the coding was verified, corrected, and saturated, a comparison across all data confirmed the tentative links and identified theoretical ideas and connections. In the theoretical coding process, issues and strategies were discovered as initial theoretical constructions. These were subcategorized to capture the complexity of the data and to refit and refine the categories for further theory building. The initial theoretical coding process was thus used to discover an emerging core category or main theme. The final outcome of the coding process was an emerging theory that facilitates understanding of the perspectives on dietary education and healthy choices in everyday life among people in Denmark with a Pakistani background and type 2 diabetes.

The following procedures were applied to increase validity and transparency: First, in the open coding phase, two researchers (Nana F Hempler and Sara Nicic) coded two interviews together. Each then independently coded an interview, and the results displayed good concordance. All differences in the coding process, however few in number, were explored and discussed; each time, the same or similar intended meanings were revealed. One researcher (Nicic) coded the remaining interviews by using the agreed approach.

The study complies with the guidelines laid down in the Declaration of Helsinki on ethical issues, and participants joined the study after informed consent. All participants gave written consent, and they were informed about anonymity and voluntary participation and that interviews would be audiotaped and transcribed. 


\section{Results}

The process of integrating and utilizing dietary education in daily life was identified as the main theme. People with a Pakistani background and type 2 diabetes described this process as challenging because of these perceived barriers: 1) a lack of a connection between the content of the education and life conditions; 2) a lack of support from the social network for dietary change; 3 ) difficulty in integrating the education into everyday life; and 4) failure to include the participants' taste preferences in the educational setting.

\section{Lack of a connection between the content of the education and life conditions}

Participants did not experience a connection between content of the diabetes dietary education and everyday life. Participants mentioned diabetes complications and other chronic diseases as barriers for practical cooking (eg, standing up and taking active part in grocery shopping); however, these barriers were not addressed in the educational setting and hence were experienced as demotivating. Participants also mentioned that challenges such as having fatigue, stress, worries, and severe illness hampered the ability to incorporate dietary knowledge into the everyday life. Another aspect concerned lack of mental resources needed to change or maintain food habits in accordance with ambitious advice about healthy choices provided in dietary education.

I have received a lot of information about what different things (food) can do and how my body will react... when I am tired, then I eat unhealthy. Yesterday, I had to work overtime and then I came home and I was too tired to cook. Then it's easier to take some chocolate cookies when your blood sugar is low. (Female, age 45)

Participants also expressed the belief that their blood glucose level reflected their general well-being and was not exclusively a result of health behaviors. For example, stress and worries affected blood glucose negatively. The lack of acknowledgement of this understanding was also experienced as a demotivating factor. Some participants described that their challenges, such as eating during the night or eating patterns when traveling or doing shift work, were often ignored as challenges by health care professionals when the participants addressed their concerns in the dietary education setting.

I said (to the health care professional) I need to get more discipline about my eating habits when I travel. She said to me, "I cannot give you a prescription for that." She said that. (Male, age 67)

Participants expressed a wish for dietary education that integrated and acknowledged the challenges that they experienced in everyday life, such as physical barriers for cooking in practice, work and life conditions, and poor general well-being.

\section{Lack of support from the social network for dietary change}

Participants described the importance of getting support from their social network in order to change or to maintain healthy dietary choices based on the received dietary education. Support was described in terms of helping participants with grocery shopping and cooking, following participants to the hospital, and supporting them in conversations about diet with health care professionals. Family was considered an important source of support because the responsibility for food, grocery shopping, and preparation often involved several household members. Several participants lived in households that comprised three generations. Participants reported that several close family members also had diabetes and, as a result, healthy food was considered important for the whole family. Sharing experiences about food with friends and learning from friends and family with diabetes was considered particularly important.

Actually a lot of people have it (diabetes), my friends too, which makes it a lot easier because then they know what (food) to make. I am a little older than them so I have had it (diabetes) for a longer time, and they are happy to get advice from me. (Female, age 64)

Although participants received support from the close family with regard to changing food habits, some explained that diabetes was considered a taboo and therefore was not discussed with people other than close family members. In addition, social practices connected to eating, such as eating during celebrations, were considered very challenging, in particular when visiting family and friends in Pakistan and during Ramadan. One participant described that it felt like he was disappearing and excluded from the community when not fasting during Ramadan because of his diabetes. Several participants expressed the dilemma of eating what is served in order to be a well-mannered guest and being part of the social practices in relation to a poorly controlled diabetes.

When I travel to Pakistan I have to eat what they make there and every time when I come back to Denmark I have to lose 
weight and the level of my sugar is so high all the time... Use extra insulin and so.....it is difficult to say anything? That would be rude....but then I say - okay, I am only here for a few days. Let me break all the rules. (Male, age 67)

Participants' wishes and attitudes with regard to dietary education included more knowledge and understanding from health care professionals about the importance of being part of the social practices and the dilemmas that those practices may entail with regard to managing diabetes in everyday life. Some participants wanted their partners to be more involved and to participate in dietary diabetes education.

\section{Difficulty in integrating the education into everyday life}

Participants expressed the belief that they had good knowledge about healthy foods, but the challenge that each person faced was to translate the knowledge provided by health care professionals into daily practice. One issue of turning knowledge into practice concerned grocery shopping and reading food labels. Participants reported buying food such as flour, rice, and beans without food labels in 'ethnic shops', which made it difficult to apply advice about studying food labels when choosing what to buy. Some also mentioned the difficulties of interpreting Danish food labels.

I usually buy the same (food), but it is limited... The same products again and again and again. When I buy something new or something special, I try to read the food labels, but it can be difficult and you don't really understand what it says. (Female, age 45)

Participants reported receiving written material (in Danish) about food from health care professionals, but they had never read it because they were not able to read Danish or did not consider it meaningful because the food culture differed significantly in terms of food preferences and choice of grocery shopping. Some participants explained that they often relied on the Internet and their social networks for information about what to eat. Some expressed that they only relied on dietary education provided by specific health care professionals such as their nurses, while others explained that they were not aware of which health care professional with whom it was appropriate to discuss issues of food.

Thus, participants wished for dietary education in a format more sensitive to linguistic challenges and thereby applicable in everyday life. Another wish concerned a more consistent contact with health care professionals whom participants were used to meeting.

\section{Participants' taste preferences not included in the educational setting}

Participants did not experience that their taste preferences were included by health care professionals in the educational setting. All participants felt they had some level of knowledge about healthy food, but they expressed frustration about being unable to adapt the received education to their food practices and preferences. In particular, the amount of oil used in cooking was mentioned by several participants as essential in making traditional Pakistani food and therefore not an option for change.

I say that without fat, then we can't cook with taste. You cannot make Pakistani food tasteless... When making real curry then afterwards we mix everything together, and then we taste it. But without that one (the oil)... we cannot.

(Male, age 64)

Participants expressed that health care professionals did not understand the importance of taste to the participants. Some participants mentioned being very conscious of their food strategies and had cut down on particular food items such as butter and bread or had replaced wheat flour with wholemeal flour for chapatti. Others had started eating rye bread (typical Danish bread) as a supplement to more traditional food. The 'rye bread strategy' was realized not because participants actually liked the taste of rye bread but because of strong recommendations of eating rye bread from health care professionals. Participants reported eating a mixture of Western and traditional Asian cuisines. Healthy food was by several participants perceived as eating Western or Danish food, whereas more traditional food was considered unhealthy because of the oil used in the cooking process. Participants described Danish food as tasteless, unlike the way they described their traditional food. Several participants had experienced that ways of cooking had been addressed in the educational setting by health care professionals, but participants reported that changing the way of preparing food, such as frying of food, was not an option because it would interfere with taste. Participants' perceptions of taste concerned more than just the tastiness; they also pertained to the appearance, temperature, and quantity of food served. Smaller portion sizes were often recommended in dietary education but this was not considered applicable in everyday life. A male participant explained the perspective:

But the problem is that our food, when it gets cold, then it doesn't taste so good. I mean when curry gets cold, half an hour or 45 minutes, then it doesn't taste so good. 
And that's why we people, we are used to eating in that way... We eat very fast. My Danish friends, they eat very slowly. (Male, age 64)

Participants' wishes and attitudes with regard to dietary education involved health care professionals putting more emphasis on how to make healthy food that is tasty and in concordance with the preferences of the individual.

\section{Discussion}

This study identified a number of patient-perceived barriers to being able to integrate and utilize dietary education provided by Danish health care professionals into everyday life for people with a Pakistani background and type 2 diabetes. Participants perceived the received dietary education as lacking a connection to life conditions and experienced difficulty in integrating the education into everyday life. The participants expressed that their taste preferences were not included in the educational setting and that they lacked support from their social networks with regard to uptake and maintenance of healthy choices. Participants wished for dietary education that was tailored to their individual needs and that addressed their taste preferences, integrated everyday challenges, involved consistent contact with health care professionals, and actively involved their partners.

People with a Pakistani background and type 2 diabetes mentioned that factors such as additional chronic diseases, stigma, fatigue, and lack of social support from the social network could hamper the ability of incorporating healthy choices in everyday life. A study by Fagerli et al found that Pakistani-born persons struggle with a different set of norms than do members of the majority population and hence experience psychological stress such as worries about family; in the article, it was also mentioned that health workers should be aware of this factor in the educational setting. ${ }^{20}$ In addition, several studies of South Asian communities have highlighted the importance of integrating the family in dietary education in order to support the person with diabetes. ${ }^{22-24}$

In a review concerning health beliefs of South Asians residing in the UK, consumption of food was found to play an important role in social networks, in the creation of social networks by giving gifts of luxurious or traditional foods, and through the social significance of cooking for guests and of eating celebratory meals. ${ }^{21}$ Participants in our study also mentioned food challenges with regard to social practices and events, such as visiting relatives in Pakistan and celebrations during Ramadan and weddings, but participants did not discuss these issues with health care professionals in the educational setting. In accordance with this, Fagerli et al report that Pakistani immigrants with type 2 diabetes perceived health care professionals' knowledge of their culture as inadequate. ${ }^{29}$

In our study, participants perceived themselves as being knowledgeable about healthy food choices. However, they faced difficulties in applying dietary knowledge provided in the diabetes educational setting into everyday life, such as when grocery shopping. As an example, they had limited possibilities of studying and understanding food labels, if these were accessible. In general, the participants perceived Western/Danish food as being healthier than Pakistani foods; however, at the same time they regarded Danish food as tasteless and plain. The dietary education implied a change of cooking methods, but some participants found that this change of cooking methods was not possible if they wanted the food to taste good and look good. Specific preferences for cooking methods and taste as well as the perception of traditional food as unhealthy have been addressed in other studies. ${ }^{20,21,23}$ As in our study, Fagerli et al also found that Pakistani participants struggled with translating dietary advice and applying it to their own life because of health workers' lack of knowledge about cross-cultural variations in dietary practices. ${ }^{20}$ Lucas et al argue that when people with South Asian background regard traditional food as risky, it is a result of a misinterpretation or misunderstanding of the dietary education provided by health care professionals. ${ }^{21}$ It is, however, also possible that health care professionals lack the skills to communicate appropriately with patients of South Asian background.

Studies concerning diet and South Asian populations have identified low income as a barrier to maintaining a healthy diet or changing to one. ${ }^{22,30}$ This was not identified in our study, a finding that may reflect differences in the standard of living between Pakistani populations in Denmark and in the UK. Fagerli et al identified a lack of interpreters as a structural barrier in consultations, whereas in this study, understanding the Danish language was perceived as a challenge in everyday life in terms of written materials from health care professionals and food labels. ${ }^{20}$

In this study, participants expressed difficulty in benefiting from the received dietary education in everyday life because it was inconsistent with their attitudes and preferences concerning taste, food choices, portion sizes, and ways of cooking and because the advice lacked a connection to life conditions. This highlights concerns about access to appropriate dietary education for people with a Pakistani background and type 2 diabetes. Generally, it is assumed that beliefs and attitudes among South Asian populations differ from those of the majority population in the host country because 
of cultural, social, and religious factors. ${ }^{16,22,30}$ Health care professionals report that they often feel poorly equipped to adequately accommodate the needs of ethnic minority groups because they lack sufficient knowledge of dietary changes that occur after immigration. ${ }^{20}$ This study also suggests that health care professionals seem to lack both the knowledge and the competency to tailor the dietary education to fit the needs and challenges of persons with a Pakistani background and type 2 diabetes.

One way of integrating preferences and attitudes in the educational setting might be in the framework of the shared decision making model, which is a process in which health care choices are made jointly by the health care professional and the patient. ${ }^{31}$ In shared decision making, it is recognized that both the professional and the patient need access to the best evidence and need to discuss this evidence in light of the patient's values and preferences and the practitioner's recommendations. However, implementing a new model such as shared decision making in the educational setting is likely to require training of the health care professionals and the diabetes service organizations.

The strengths of our study include the inductive and systematic approach to the analysis, an approach which was proved useful in identifying perspectives, experiences, and preferences regarding dietary education of people with a Pakistani background and type 2 diabetes. The limitations include our approach to gathering subjects for this study; although we applied a purposeful sampling strategy, participants were exclusively recruited from one region of Denmark. A potential limitation includes the transferability of the findings beyond the participants of this study. Participants varied with regard to the extent and intensity of the dietary education that they received and also with regard to the professional background of the health care professional who had provided the education; some mentioned that they had received counseling by the nurse or the doctor. It is also likely that some participants had received dietary education in other settings such as health centers or by their general practitioners. Variations among participants in our study also highlight the need to be aware of the contextual diversity within the group. Also, it is unknown whether the participants originated from the same region of Pakistan, although most Pakistani immigrants in Denmark have emigrated from the Punjab region. It does not seem appropriate to apply stereotypical assumptions about people because of a particular ethnic background.

Validity rests on the researcher's ability to continuously reflect upon, question, and discuss previous understandings and interpretation of data during the entire process. Validity was sought by discussion of interviews between researchers (Hempler and Nicic), reading field notes, and listening to recordings of the interviews. Interviews conducted in a language other than the language spoken by the researcher may be challenging because of stifled discussions and compromised data quality. ${ }^{32}$ In order to reduce these potential challenges, the researcher used the same interpreter for the interviews and met with the interpreter beforehand with the purpose of discussing the interview approach. Also, by approaching the interviewees with empathy and acknowledgement, we strived to facilitate a trustful relationship. However, participants' perceptions of the interviewer may have influenced the findings; some participants may have chosen not to mention particular perspectives because the interviewer was employed at the specialist diabetes clinic where the participants received or previously received treatment.

\section{Conclusion}

This study suggests that people with a Pakistani background and type 2 diabetes do not consider the dietary education that they received appropriate because of lack of sensitivity to their wishes, attitudes, and preferences. The applicability of dietary education may be increased if the content and format are considered relevant by people with a Pakistani background and type 2 diabetes. Dietary education that identifies and aims at establishing a connection to everyday life for the participants might facilitate successful changes in dietary practices. Such a process requires improvements in the skills and knowledge of health care professionals who provide the dietary education as well as an understanding of how best to organize diabetes services for ethnic groups.

\section{Acknowledgments}

We thank all the participants for taking time to be interviewed and thank Kamran Akram and Lotte Vinther for helping with recruitment of participants. We thank Jennifer Green, Caduceus Strategies, for editorial assistance.

\section{Author contributions}

Nana F Hempler designed the study, conducted the interviews, analyzed the data, and drafted the submitted manuscript. Sara Nicic analyzed the data, contributed to writing the manuscript, and approved the submitted version. Bettina Ewers contributed to data analysis, critically revised the manuscript, and approved the submitted manuscript. Ingrid Willaing contributed to study design and data analysis, critically revised the manuscript, and approved the submitted manuscript. 


\section{Disclosure}

Nana F Hempler, Sara Nicic, Bettina Ewers, and Ingrid Willaing are employed by Steno Diabetes Center A/S, a diabetes research hospital working in the Danish National Health Service and owned by Novo Nordisk A/S. This research did not receive any specific grants from any funding agencies or from commercial or not-for-profit sectors. The authors report no other conflicts of interest.

\section{References}

1. Rafnsson SB, Bhopal RS. Large-scale epidemiological data on cardiovascular diseases and diabetes in migrant and ethnic minority groups in Europe. Eur J Public Health. 2009;19(5):484-491.

2. Agyemang C, Kunst AE, Bhopal R, et al. Diabetes prevalence in populations of South Asian Indian and African origins: a comparison of England and the Netherlands. Epidemiology. 2011;22(4):563-567.

3. Jayawardena R, Ranasinghe P, Byrne NM, Soares MJ, Katulanda P, Hills AP. Prevalence and trends of the diabetes epidemic in South Asia: a systematic review and meta-analysis. BMC Public Health. 2012; $12: 380$.

4. Misra A, Ganda OP. Migration and its impact on adiposity and type 2 diabetes. Nutrition. 2007;23(9):696-708.

5. Abate N, Chandalia M. Ethnicity and type 2 diabetes: focus on Asian Indians. J Diabetes Complications. 2001;15(6):320-327.

6. Tillin T, Forouhi N, Johnston DG, McKeigue PM, Chaturvedi N, Godsland IF. Metabolic syndrome and coronary heart disease in South Asians, African-Caribbeans and white Europeans: a UK populationbased cross-sectional study. Diabetologia. 2005;48(4):649-656.

7. Wändell PE, Carlsson A, Steiner KH. Prevalence of diabetes among immigrants in the Nordic countries. Curr Diabetes Rev. 2010;6(2):126-133.

8. Statistics Denmark. Indvandrere i Danmark 2013 [Immigrants in Denmark 2013]. Statistics Denmark; 2013. Available from: http://www. dst.dk/pukora/epub/upload/17961/indv2013.pdf. Assessed January 20, 2015.

9. IDF Diabetes Atlas, Sixth edition [webpage on the Internet]. Brussels: International Diabetes Foundation; 2014. Available from: http://www. idf.org/atlasmap/atlasmap. Accessed November 11, 2014.

10. Singhammer J, Storgaard SF, Mygind A, et al. Etniske minoriteters sundhed [The health of ethnic minorities]. Centre for Public Health, Central Denmark Region; 2008. Available from: http://www.cfk. $\mathrm{rm} . \mathrm{dk} /$ files/Sundhed/CFK/Projekter/HHDD\%20-\%20sundhedsprofil/ Etnisk\%20sundhedsprofil_juni\%202008.pdf. Assessed January 20, 2015.

11. Holmboe-Ottesen G, Wandel M. Changes in dietary habits after migration and consequences for health: a focus on South Asians in Europe. Food Nutr Res. 2012;56.

12. Shah A, Kanaya AM. Diabetes and Associated Complications in the South Asian Population. Curr Cardiol Rep. 2014;16(5):476.

13. Evert AB, Boucher JL, Cypress M, et al. Nutrition therapy recommendations for the management of adults with diabetes. Diabetes Care. 2014; 37 (Suppl 1):S120-S143.

14. Szczepura A. Access to health care for ethnic minority populations. Postgrad Med J. 2005;81(953):141-147.

Patient Preference and Adherence

\section{Publish your work in this journal}

Patient Preference and Adherence is an international, peer-reviewed, open access journal that focuses on the growing importance of patient preference and adherence throughout the therapeutic continuum. Patient satisfaction, acceptability, quality of life, compliance, persistence and their role in developing new therapeutic modalities and compounds to optimize
15. Atkinson M, Clark M, Clay D, Johnson M, Owen D, Szczepura A. Systematic Review of Ethnicity and Health Service Access for London. London: London Regional Office of NHS Executive; 2001. Available from: http://mighealth.net/uk/images/5/56/System.doc. Accessed November 11, 2014.

16. Resnicow K, Baranowski T, Ahluwalia JS, Braithwaite RL. Cultural sensitivity in public health: defined and demystified. Ethn Dis. 1999; 9(1):10-21.

17. Baradaran HR, Knill-Jones RP, Wallia S, Rodgers A. A controlled trial of the effectiveness of a diabetes education programme in a multi-ethnic community in Glasgow [ISRCTN28317455]. BMC Public Health. 2006;6:134

18. O'Hare JP, Raymond NT, Mughal S, et al; UKADS Study Group. Evaluation of delivery of enhanced diabetes care to patients of South Asian ethnicity: the United Kingdom Asian Diabetes Study (UKADS). Diabet Med. 2004;21(12):1357-1365.

19. Khunti K, Camosso-Stefinovic J, Carey M, Davies MJ, Stone MA. Educational interventions for migrant South Asians with Type 2 diabetes: a systematic review. Diabet Med. 2008;25(8):985-992.

20. Fagerli RA, Lien ME, Wandel M. Experience of dietary advice among Pakistani-born persons with type 2 diabetes in Oslo. Appetite. 2005; 45(3):295-304

21. Lucas A, Murray E, Kinra S. Heath beliefs of UK South Asians related to lifestyle diseases: a review of qualitative literature. J Obes. 2014;2014: 827674.

22. Greenhalgh T, Helman C, Chowdhury AM. Health beliefs and folk models of diabetes in British Bangladeshis: a qualitative study. BMJ. 1998;316(7136):978-983.

23. Lawton J, Ahmad N, Hanna L, Douglas M, Bains H, Hallowell N. 'We should change ourselves, but we can't': accounts of food and eating practices amongst British Pakistanis and Indians with type 2 diabetes. Ethn Health. 2008;13(4):305-319.

24. Mian SI, Brauer PM. Dietary education tools for South Asians with diabetes. Can J Diet Pract Res. 2009;70(1):28-35.

25. Partridge R. Post-licensure baccalaureate education for registered nurses. In BG Glaser, editor. Gerund Grounded Theory: The Basic Social Process Dissertation. Mill Valley: Sociology Press; 1996:73-84.

26. Gaver B, Dunne T, Pancetti E. Design:cultural probes. Interactions. 1999;6(1):21-29.

27. Glaser BG. Theoretical Sensitivity: Advances in the Methodology of Grounded Theory. 1th ed. Mill Valley: Sociology Press; 1978.

28. Heath H, Cowley S. Developing a grounded theory approach: a comparison of Glaser and Strauss. Int J Nurs Stud. 2004;41(2):141-150.

29. Fagerli RA, Lien ME, Wandel M. Health worker style and trustworthiness as perceived by Pakistani-born persons with type 2 diabetes in Oslo, Norway. Health (London). 2007;11(1):109-129.

30. Bissell P, May CR, Noyce PR. From compliance to concordance: barriers to accomplishing a re-framed model of health care interactions. Soc Sci Med. 2004;58(4):851-862.

31. Légaré F, Turcotte S, Stacey D, Ratté S, Kryworuchko J, Graham ID. Patients' perceptions of sharing in decisions: a systematic review of interventions to enhance shared decision making in routine clinical practice. Patient. 2012;5(1):1-19.

32. Kosny A, MacEachen E, Lifshen M, Smith P. Another person in the room: using interpreters during interviews with immigrant workers. Qual Health Res. 2014;24(6):837-845.

clinical outcomes for existing disease states are major areas of interest for the journal. This journal has been accepted for indexing on PubMed Central. The manuscript management system is completely online and includes a very quick and fair peer-review system, which is all easy to use. Visit http://www. dovepress.com/testimonials.php to read real quotes from published authors. 